\title{
Vasoactive intestinal peptide alleviates osteoarthritis effectively via inhibiting NF-KB signaling pathway
}

Yaozhong Liang ${ }^{1}$, Shu Chen², Yuhao Yang ${ }^{1}$, Chunhai Lan ${ }^{1}$, Guowei Zhang ${ }^{1}$, Zhisheng Ji ${ }^{1}$ and Hongsheng Lin ${ }^{\text {* }}$

\begin{abstract}
Background: To investigate the treatment effect of vasoactive intestinal peptide (VIP) on osteoarthritis (OA) and the relative mechanism.

Method: The OA model on the SD rat knee was established using the modified Hulth method, and the recombinant pcDNA3.1+NIP plasmid was constructed. One month after the plasmids VIP were injected intra-articularly into the right knee joint of OA and sham-operated rats, the pathological changes of the OA knee joint were observed by Hematoxylin-eosin (HE) and Safranin O/fast green staining. The levels of VIP and serum inflammatory cytokines (TNF-a, IL-2 and IL-4) were measured by ELISA kits. Meanwhile, synoviocytes isolated from OA rat and sham-operated rat were cultured in vitro, and transfected with the VIP plasmid. The proliferation of synoviocytes was determined using BrdU kits. The protein expressions of TNF-a, IL-2, CollagenII, osteoprotegerin (OPG), matrix-degrading enzymes (MMP-13, ADAMTS-5), and the related protein of NF-kB signaling pathway (phosphorylated p65, phosphorylated lkBa) were evaluated by western blot.
\end{abstract}

Results: The VIP plasmid could effectively improve the pathological state of the OA rats knee joint, significantly decrease the levels of serum TNF-a and IL-2, and clearly increase the levels of VIP and serum IL-4. At the same time, after the OA synoviocytes were treated with the VIP plasmid, the proliferation ability of OA synoviocytes was reduced, the protein expressions of Collagen II and OPG were remarkably up-regulated, and the protein expressions of TNF-a, IL-2, MMP-13 and ADAMTS-5 were significantly down-regulated. In addition, the p-p65 expression decreased and $\mathrm{p}-\mathrm{I} \mathrm{KB}$ a expression increased.

Conclusion: Osteoarthritis was effectively treated by VIP via inhibiting the NF-KB signaling pathway.

Keywords: Vasoactive intestinal peptide, Osteoarthritis, Synoviocytes, NF-kB signaling

\section{Background}

Osteoarthritis (OA) is a common chronic degenerative and disabling joint disease, that has a high incidence in the elderly, and seriously affects people's health and quality of life [1]. Today, OA is considered as a major public health problem worldwide, and the prevalence of OA increases year after year. By 2030, it is predicted that in the United States 67 million people will be diagnosed with OA [2]. Clinically, the disease is characterized by persistent joint pain and joint disorder, accompanied by

\footnotetext{
* Correspondence: linhs2016@sina.com

${ }^{1}$ Department of Orthopedics, The First Affiliated Hospital of Jinan University, Guangzhou 510630, China

Full list of author information is available at the end of the article
}

a gradual loss of articular cartilage, osteophyte formation, subchondral bone sclerosis, synovium inflammation, the proliferation of synoviocytes, and joint function $[3,4]$. It was reported that the occurrence of OA is associated with a variety of factors, such as age, trauma, and genetic factors, but no significant racial and geographical differences have been described [5]. However, until now, the exact causes and pathogenesis of OA have not been entirely clear, and in the clinic, there is no effective therapeutic strategy to treat OA. Therefore, in recent years, clarifying the pathogenesis of $\mathrm{OA}$ and finding an effective method for its treatment have gained more and more attention. 
Vasoactive intestinal peptide (VIP) is an immunologically active neuropeptide, that has anti-inflammatory and immune-regulating effects. It has been reported that VIP can relieve and treat experimental arthritis [6, 7]. Moreover, Jiang et al. [8] demonstrated that VIP is a potential indicator of severity of OA. However, due to the short half-life and fast metabolism of VIP in vivo, and because the long-term injection of VIP will cause immune suppression and gastrointestinal disorders, the clinical application of VIP is greatly restricted [9]. Recently, gene therapy has been developed to effectively avoid these side effects.

Therefore, in the present study, the VIP recombinant plasmid was constructed, and the OA model rat was established using modified Hulth method. Then, the effect of VIP recombinant plasmid on OA model rat was investigated in vivo. In addition, an OA synoviocyte model was established, and the cultured OA synoviocytes with or without VIP recombinant plasmid were evaluated in vitro. Furthermore, the underlying mechanism of VIP was explored.

\section{Materials and methods Materials}

VIP primer was synthesized by Sangon Biotech (Shanghai) Co., Ltd. (Shanghai, China). EcoR I and Hind III were obtained from MBIFermentas (Vilnius, Lithuania). Cell culture medium and supplements were purchased from Gibco (Mountain View, CA, USA). pcDNA3.1, Lipofectamine 2000 and TRizol were obtained from Invitrogen Corp. (Carlsbad, California, USA). The VIP ELISA assay kit was purchased from Solarbio (Shanghai, China). TNF- $\alpha$ ELISA assay kit, IL-2 ELISA assay kit, IL-4 ELISA assay kit and the 5-bromo-2-deoxyuridine (BrdU) cell proliferation assay kits were purchased from Merck MilliporeCorp (Darmstadt, Hesse, Germany). Antibodies of VIP, TNF- $\alpha$, IL-2, CollagenII, OPG, MMP-13 and ADAMTS-5 were purchased from Abcam (Cambridge, MA, USA). Antibodies of Vimentin, p65, p-p65, IкB $\alpha$, $\mathrm{p}-\mathrm{I} \kappa \mathrm{B} \alpha, \beta$-actin and IgG were purchased from Cell Signaling Technology. Inc. (Danvers, MA, USA).

\section{Methods}

\section{Construction of VIP recombinant plasmid}

VIP recombinant plasmid was constructed according to a previously reported method [10, 11]. Briefly, mouse thymocytes were taken and total RNA was extracted using TRIzol reagent. Then, $1 \mu \mathrm{g}$ of total RNA was used to clone VIP cDNA by RT-PCR. The primers used were as follows: F-GCCAAGCTTATGGACACCAGAAATAA GGCCCAGCTCCTTGTGCTCCTGACTCTTCTCAGT GAGCTCTTCTCACACTCTGATGCCGTCTTC; R-CG GAATTCTCAATTCAGGATGGAGTTCAG-3. The reaction conditions were as follows: $94{ }^{\circ} \mathrm{C} 3 \mathrm{~min}, 94{ }^{\circ} \mathrm{C} 30 \mathrm{~s}$, $58{ }^{\circ} \mathrm{C} 30 \mathrm{~s}, 72{ }^{\circ} \mathrm{C} 30 \mathrm{~s}$ for 5 cycles; $94{ }^{\circ} \mathrm{C} 30 \mathrm{~s}, 68^{\circ} \mathrm{C} 30 \mathrm{~s}$,
$72{ }^{\circ} \mathrm{C} 30 \mathrm{~s}$ for 25 cycles, and $72{ }^{\circ} \mathrm{C}$ extension for $10 \mathrm{~min}$. The PCR products were identified by electrophoresis in a $2 \%$ agarose gel. PCR products were digested by EcoR I and Hind III, and the target fragments were then recovered and directed to the eukaryotic expression vector pcDNA3.1 treated with the same double digestion and recovered with $\mathrm{T}_{4}$ DNA ligase. Then, DH5 $\alpha$ bacteria were transformed, and plasmid was extracted and enzyme digested. Subsequently, the products were identified by electrophoresis and sequencing.

\section{Establishment of OA rat model}

Fifty-six SD male rats (5 weeks old, 250-280 g in weight) were purchased from Guangdong Pharmaceutical University. Rats had access to water and food ad libitum, and were maintained under a 12-h light/dark cycle, at a controlled room temperature $\left(25 \pm 1{ }^{\circ} \mathrm{C}\right)$. The animal experimental protocols and the use of chloral hydrate as a surgical anesthetic were approved by the guidelines of Animal Care and Use Committee of Guangdong Pharmaceutical University. All experimental procedures were performed in compliance with the NIH Guide for the Care and Use of Laboratory Animals and National Animal Welfare Law in China.

The OA rat model was established by performing unilateral knee joint surgery using a modified Hulth method as described by Hayami et al. [12]. Twenty-eight rats (5 weeks old, 250-280 g in weight) were randomly selected and anesthetized with $10 \%$ chloral hydrate $(4 \mathrm{~mL} / \mathrm{kg}$, i.p.) according to previous reports [13]. Then, the rats were laid supine on the operating table and received hair removal and povidone-iodine disinfection. The right knee joint cavity of rat was exposed via a medial parapatellar incision. Subsequently, the anterior cruciate ligamentand medial collateral ligament were cut off, and medial meniscus was resected. Then, the incisions were sutured layer by layer. After the surgery, to prevent infection, the rats received $20,000 \mathrm{U}$ penicillin intramuscular injections every day for a week. The remaining twenty-eight SD rats were grouped in the sham surgery group; these rats were treated in the same manner as the OA rat model, but the anterior cruciate ligament and medial collateral ligament were not cut off, and the medial meniscus was not removed. Four weeks after surgery, four rats from the sham-operated group and OA model group were randomly selected for sacrifice to verify by pathological observation whether the $\mathrm{OA}$ rat model set up successfully.

\section{Grouping and administration}

The sham-operated and OA rats were both randomly divided into two groups: sham+control plasmid (A), sham+VIP plasmid (B), OA + control plasmid (C) and $\mathrm{OA}+$ VIP plasmid (D). After anesthesia, the rats in groups $\mathrm{A}$ and $\mathrm{C}$ and groups $\mathrm{B}$ and $\mathrm{D}$ received intra-articular 
injection of $15 \mu \mathrm{L}$ of control plasmid or VIP plasmid (pcDNA3.1+/VIP $30 \mu \mathrm{g}$ ), respectively, into surgical site once a week for 4 consecutive weeks. During the experiment, the rats were allowed free access to food and water, and the state of rats were observed every day to avoid any adverse events. Two hours after the last administration, $5 \mathrm{~mL}$ of whole blood was obtained from the abdominal aorta, and centrifuged immediately. Collected the supernatant and placed at $4{ }^{\circ} \mathrm{C}$ until measured. The rats were subsequently euthanized by inhalation of carbon dioxide. Additionly, in each group of rats, the right knee joints were taken and the synovial tissue was separated, and then stored at $-20{ }^{\circ} \mathrm{C}$ before the assay.

\section{Histological examination of knee joint}

The tissues of rat knee joints were fixed in $10 \%$ paraformaldehyde and decalcified in 20\% EDTA solution. Then, the specimens were cut along the sagittal plane, which were then dehydrated in ethanol step by step, vifrificated in xylene and embedded in paraffin. Subsequently, the specimens were cut into 4.0 5.0 $\mu \mathrm{m}$ sections, then stained with $\mathrm{HE}$ and Safranin $\mathrm{O} /$ fast green. Histological changes were observed under a light microscope.

The Osteoarthritis Research Society International (OARSI) Scoring System was used to analyze cartilage degenerative status described previously as follows [14]:The structure was scored on a scale of $0-6$, where $0=$ surface intact, cartilage morphology intact; $1=$ surface intact; $2=$ surface discontinuity; $3=$ vertical fissures (clefts); $4=$ erosin; $5=$ denudation; $6=$ deformation. Histological evaluation was performed by two independent experienced researchers who were blinded to information of the study.

\section{Detection of serum VIP and cytokines}

The serum VIP and serum cytokine (TNF- $\alpha$, IL-2 and IL-4) levels in each group were measured using ELISA assay kits according to the manufacturer's instructions. Optical density was detected at $450 \mathrm{~nm}$ through a SpectraMax M5 autoreader.

\section{Isolation and culture of synoviocytes}

Synoviocytes were isolated using the type II collagenase digestion method. First, Synovial tissues of OA rats and sham rats were taken and minced for digestion with $0.2 \%$ collagenase II for $3 \mathrm{~h}$. Then, the solutions were filtered using a 200 mesh sieve to collect the filtrate and were centrifuged at $1200 \mathrm{r} / \mathrm{min}$ for $5 \mathrm{~min}$. Subsequently, the supernatant was discarded, and the appropriate amount of DMEM culture medium containing 10\% FBS (Gibco) were added. Finally, the cells were cultured in a $37{ }^{\circ} \mathrm{C}$, $5 \% \mathrm{CO}_{2}$ incubator, and the medium was changed once every $48 \mathrm{~h}$. The growth of the cells was observed under an inverted microscope. When the confluence reached approximately $80 \%$, the cells were passaged. The cells of generation 3 were were used for the following experiments. Cells isolated from sham and OA rats were named as sham and OA synoviocytes, respectively, and they were identified by immunofluorescence staining.

\section{Transfection}

The synoviocytes were plated at a density of $3 \times 10^{5}$ per well on 6-well plate in DMEM containing 10\% FBS. When the cells grew to approximately $80 \%$ confluence, they were then transfected with $10 \mathrm{nM}$ of VIP plasmid or empty-pcDNA3.1vector (as NC plasmid) by Lipofectamine 2000 reagent for $48 \mathrm{~h}$ following the instructions of manufacturer.

\section{Cell proliferation assay}

Cell proliferation was detected by the BrdU Cell Proliferation assay kit according to the manufacturer's instructions.

\section{Western blotting}

The cells were lysed with RIPA and centrifuged. Protein concentrations were detected using the BCA protein assay kit. The protein was fractionated using SDS-PAGE and transferred onto PVDF membrane. Before incubating with antibodies, membranes were first blocked for in 5\% skim- milk. Then the membranes were incubated with primary antibodies at $4{ }^{\circ} \mathrm{C}$ overnight, followed incubated with HRP-conjugated IgG antibody at room temperature for $1 \mathrm{~h}$. Finally, the protein was visualized using the ECL kit and observed by the GeneGnome machine (Syngene).

\section{Statistical analysis}

All data are presented as the $\bar{x} \pm \mathrm{SD}$ and were analyzed using SPSS 13.0 software. Comparisons between groups were processed by one-way analysis of variance, with $P<0.05$ considered significant.

\section{Results \\ Histological changes}

To observe the effect of VIP plasmid on the OA knee joint, HE and Safranin O-fast green staining were performed. As shown in Fig. 1a, there was no significant changes of pathological features between the rats' knee joint in sham+control and sham+VIP plasmid group, and smooth joints surface, clearly visible cartilage structure, a complete tide line were observed. However, in the OA + control-plasmid group, there were some fractures in the surface, the numbers of chondrocytes notably reduced, cells were diffusely increased, and a large number of cells clusters appeared, which was consistent with the basic pathological changes of osteoarthritis. In contrast, in the OA model rats treated with VIP plasmid, the pathological changes of the rat knee were significantly improved. Consistently, as shown in Fig. 1b, we found that the OARSI 


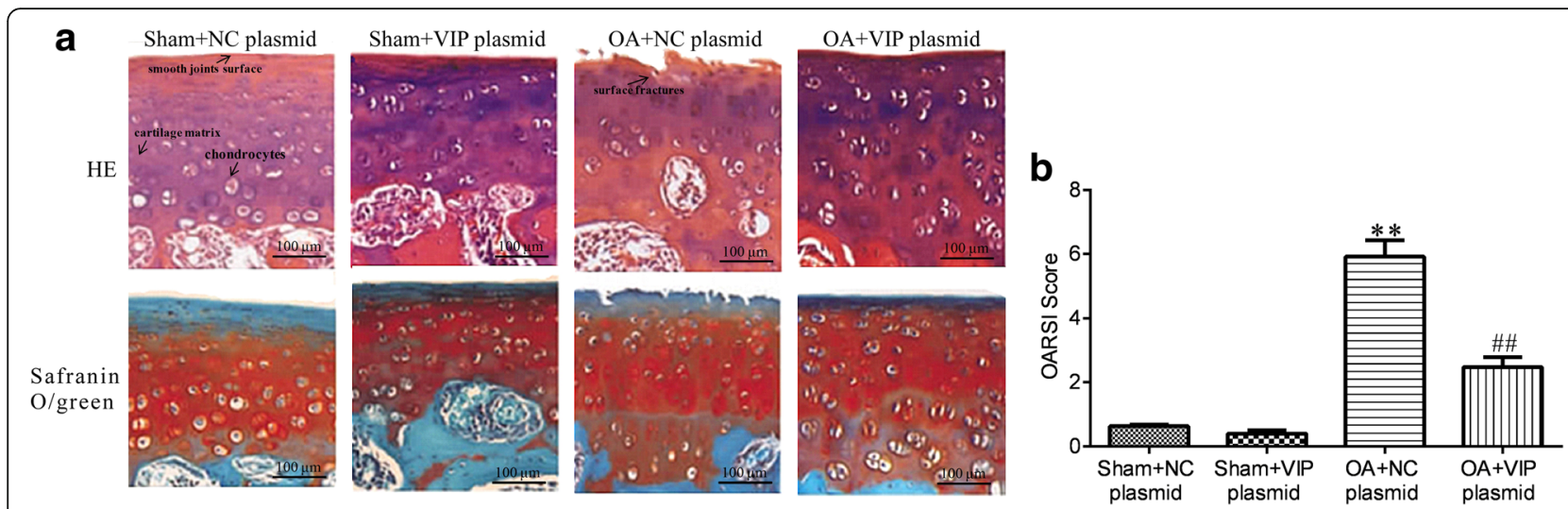

Fig. 1 Histopathologic profiles of rat knee joints in each group by hematoxylin and eosin (HE) staining and Safranin O/fast green staining (a) and OARSI score (b). (Scale bar $=100 \mu \mathrm{m}$ )

score in OA + VIP plasmid group was significantly lower than that in $\mathrm{OA}+$ control plasmid group. After conducting statistical analysis, there were significant differences in the OARSI scores after the injections of VIP plasmid compared to OA model rat treated with control plasmid alone $(P<0.01)$.

\section{Analysis of the serum VIP and serum cytokines}

The serum VIP and cytokine levels of TNF- $\alpha$, IL-2, IL-4 in each group are shown in Table 1. It showed that compared with sham+control-plasmid group, the serum level of VIP in OA rats which treated with control-plasmid was significantly lower, as the VIP concentrations of the two groups were $68.8 \pm 9.7 \mathrm{pg} / \mathrm{mL}$ and $29.5 \pm$ $12.4 \mathrm{pg} / \mathrm{mL}$, respectively, whereas the VIP plasmid treatment in OA rats obviously up-regulated the VIP serum level to $57.6 \pm 10.1 \mathrm{pg} / \mathrm{mL}$. For the serum cytokine levels, it was found that the serum levels of TNF- $\alpha$ and IL-2 in OA + control plasmid group were significantly increased and that the serum level IL-4 was obviously decreased compared to the sham+control plasmid group and sham+VIP group $(P<0.05)$. However, in the OA rats treated with VIP plasmid, the serum cytokine levels restored to those in sham+control plasmid group or sham+VIP group, because the serum levels of TNF- $\alpha$ and IL- 2 were markedly down-regulated, and IL- 4 was significantly up-regulated $(P<0.05)$.

\section{Identification of synoviocytes}

As shown in Fig. 2a, we found that the cellular morphology of the cells isolated from sham and OA model rats were all fibroblast-like. Additionally, immunofluorescence staining showed vimentin positively expressed in the cytoplasm of the two types of cells. These findings suggested that the cultured cells isolated from sham and OA rats were all fibroblast-like synoviocytes.

\section{Detection of transfection efficiency}

To verify the transfection efficiency, the expression of VIP in transfected OA synoviocytes was detected. As shown in Fig. 2b, the level of VIP maintained at different culture time for 14 days, that the expression of VIP was gradually increased with time before the synoviocytes were cultured for 7 days. and it reached the maximum after the cells were cultured for 7 days but then declined over the next few days. Meanwhile, we also observed that the expression level of VIP in the OA synoviocytes which transfected with control-plasmid $(\mathrm{OA}+\mathrm{NC}$ plasmid group) was very low, while it increased markedly in VIP plasmid transfected synoviocytes (Fig. 2c).

\section{VIP inhibits the proliferation of synoviocytes}

After transfection for $48 \mathrm{~h}$, the cell proliferation were detected. As shown in Fig. 2d, the ability of synoviocytes proliferation in $\mathrm{OA}+$ control plasmid group increased notably compared with sham+control plasmid group,

Table 1 Levels of Serum VIP and cytokines in each group $(\bar{x} \pm \mathrm{SD}, n=12)$

\begin{tabular}{lllll}
\hline Group & VIP $(\mathrm{pg} / \mathrm{mL})$ & TNF-a $(\mathrm{pg} / \mathrm{mL})$ & $\mathrm{IL}-2(\mathrm{pg} / \mathrm{mL})$ & $\mathrm{IL}-4(\mathrm{pg} / \mathrm{mL})$ \\
\hline Sham+NC plasmid & $68.8 \pm 9.7$ & $106.1 \pm 8.3$ & $130.3 \pm 10.5$ & $41.2 \pm 9.3$ \\
Sham+VIP plasmid & $73.4 \pm 11.6$ & $101.3 \pm 10.8$ & $122.1 \pm 9.9$ & $46.7 \pm 8.4$ \\
OA + NC plasmid & $29.5 \pm 12.4^{*}$ & $184.9 \pm 8.6^{*}$ & $174.3 \pm 12.7^{*}$ & $14.7 \pm 6.6^{*}$ \\
OA + VIP plasmid & $57.6 \pm 10.1^{\#}$ & $112.8 \pm 10.2^{\#}$ & $131.4 \pm 13.4^{\#}$ & $43.8 \pm 8.7^{\#}$ \\
\hline
\end{tabular}

Compared with Sham+NC plasmid group, ${ }^{*} P<0.05$; Compared with OA + NC plasmid group, ${ }^{\#} P<0.05$ 

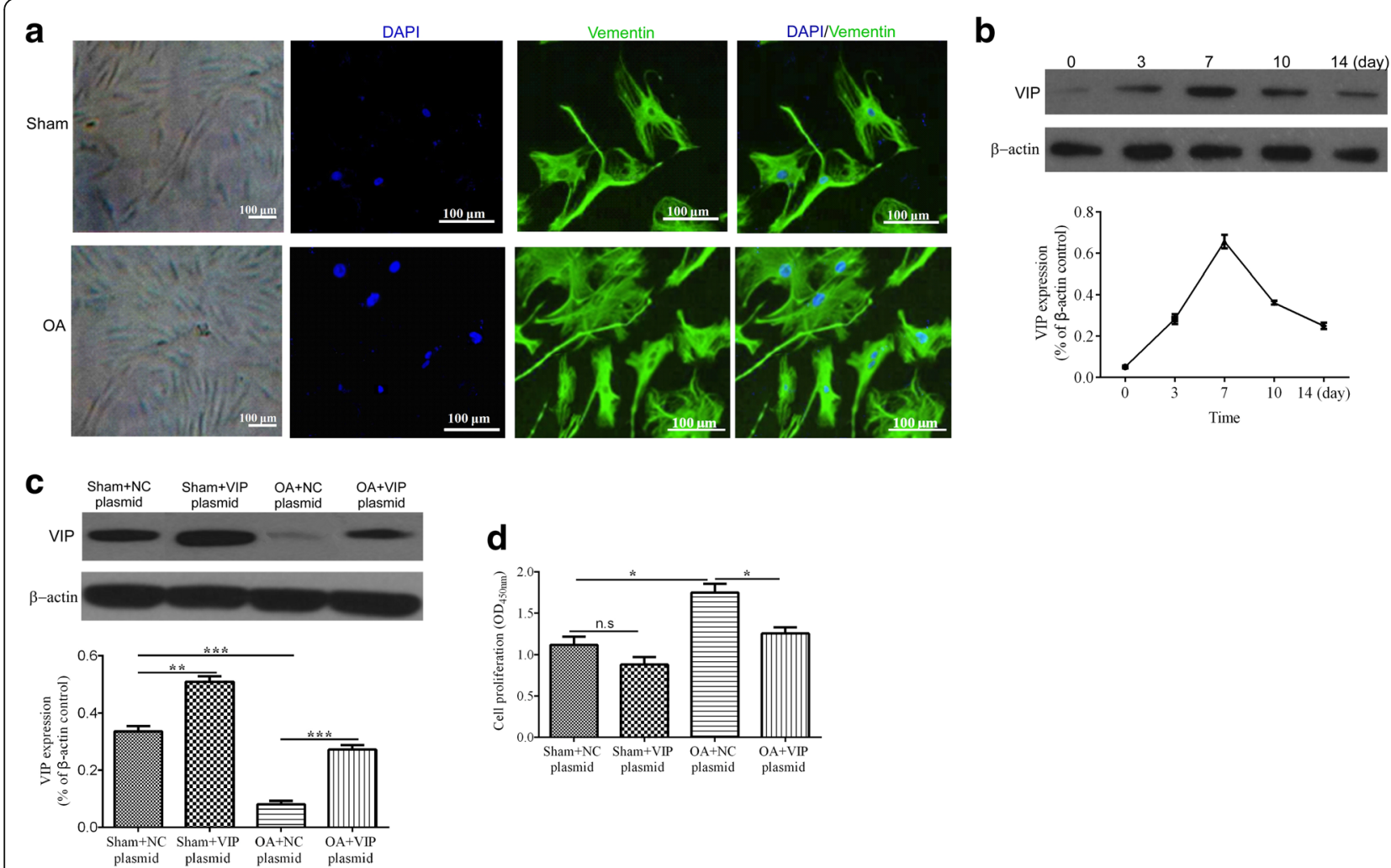

Fig. 2 Light optical microscope and immunofluorescence staining of vimentin pictures of synoviocytes (a). VIP expression in OA-synoviocytes during culture for 14 days (b), culture for 2 days in 4 groups (c). VIP plasmid inhibits the proliferation of synoviocytes $(\mathbf{d}) .{ }^{*} P<0.05$, ${ }^{* *} P<0.01$, ${ }^{* * *} P<0.001$, and n.s means no statistical difference

and the difference was statistically significant $(P<0.01)$. However, in the OA + VIP plasmid group, the proliferation ability of synoviocytes decreased obviously, with levels close to the sham synoviocytes.

\section{Effect of VIP plasmid on the biomarkers of synoviocytes} As is shown in Fig. 3, the effect of VIP plasmid on the protein expressions of TNF- $\alpha$, IL-2, Collagen II, OPG, MMP-13 and ADAMTS-5 were displayed. Compared with the sham+control-plasmid and VIP plasmid groups, in the $\mathrm{OA}+$ control-plasmid group, the protein expressions of TNF- $\alpha$, IL-2, MMP-13 and ADAMTS- 5 were obviously increased, and the protein expressions of Collagen II and OPG in the OA synoviocytes were significantly decreased. However, in the OA synoviocytes cultured with VIP plasmid in OA + VIP plasmid group, the protein expressions of TNF- $\alpha$, IL-2, MMP-13 and ADAMTS- 5 were up-regulated, and the protein expressions of Collagen II and OPG were down-regulated.

\section{Effect of VIP plasmid on NF-KB signaling pathway}

To investigate the mechanism of VIP plasmid treatment on synoviocytes, we further detected the expression of related molecular in NF- $\mathrm{KB}$ signal pathway, including p65 and IкB $\alpha$. As is shown in Fig. 4, compared with synoviocytes of sham rats, the expression of p-p65 and $\mathrm{p}$ - IкB $\alpha$ in synoviocytes of OA rats up-regulated and down-regulated significantly, respectively $(P<0.05)$. However, after VIP plasmid transfected, the expression of p-p65 and p- ІкB $\alpha$ in synoviocytes of OA rats decreased and increased notably compared with those in synoviocytes of $\mathrm{OA}+\mathrm{NC}$ group, which indicates the treatment of VIP plasmid could effectively inhibit the NF- NF- $k B$ signal pathway in synoviocytes.

\section{Discussion}

Until now, in the clinical, an effective treatment strategy for OA still has been lacking. VIP, which composed of 28 amino acid residues, is a neuropeptide with antiinflammatory and immune regulation that participates in the reconstruction of bone resorption, metabolism and fracture healing. In addition, previous researches have shown that VIP could effectively improve the symptoms of arthritis and inhibit cartilage damage [15, 16]. VIP has a short half-life and fast metabolism in vivo, and the longterm injection of VIP will produce immune suppression and gastrointestinal disorders. However, gene therapy may effectively avoid these problems. More importantly, VIP plasmid treating for OA has not been reported before in the literature. Therefore, in this study, we investigate the 

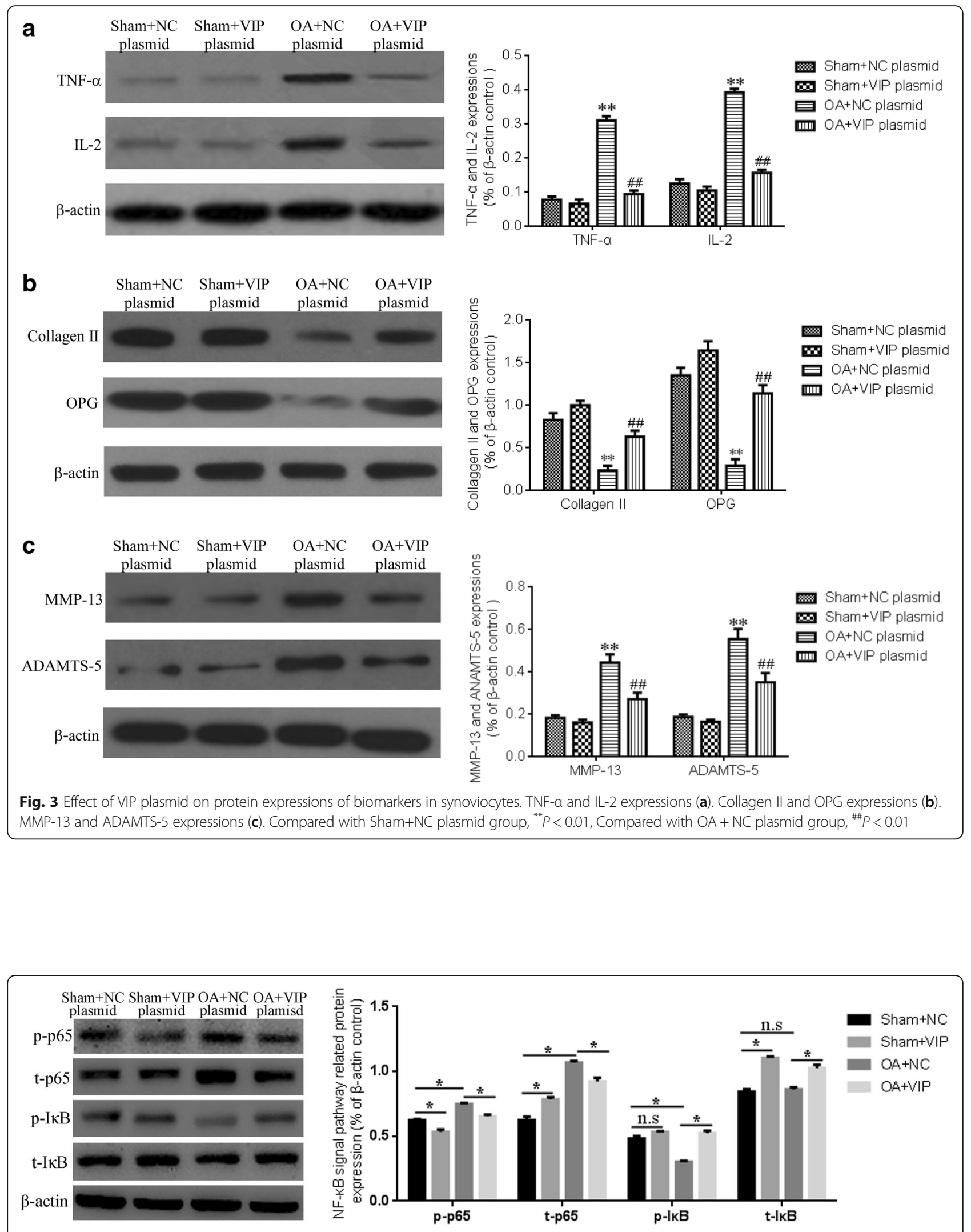

Fig. 4 The effect of VIP plasmid on protein expression of NF-KB signaling. p-p65 and p-IKBa were the phosphorylated form of p65 and IKBa, respectively; t-p65 and t-IKBa were the total of $\mathrm{p} 65$ and IKBa, respectively. Left: detected via western blot; Right: relative expression 
pathogenesis of OA and the effect of VIP plasmid on treating OA.

Firstly, we observed the effects of VIP plasmid treating for OA through establishing OA model. The results showed the pathological symptoms of OA rats were markedly improved after VIP plasmid intervention. Previously, Jiang et al. measured the VIP level of fifty patients with primary knee OA and found the VIP level in OA patients were much lower than that in heathly people, and this difference was negatively associated with progressive joint damage in OA [8]. In our study, we also found that VIP levels in $\mathrm{OA}$ rats were significantly lower than that in sham-operated rats. Moreover, TNF- $\alpha$ is an important pro-inflammatory cytokine, and can start a cascade reaction which are directly involved in the pathological changes of OA. Studies reported IL-4 has chondro protective effects, which will decrease as cartilage degraded [17]. In this study, we found that compared with the sham-operated rats, the expression of TNF- $\alpha$ and IL-2 increased, and IL-4 decreased in OA rats. In contrast, in rats of OA + VIP plasmid group, these inflammatory cytokines were markedly restored. These findings were consistent with a previous study that reported VIP had anti-inflammatory activity [18]. Therefore, this study suggested that to some degree, VIP plasmid has a treatment function in OA rats.

Hitherto, the pathogenesis of OA still remained unclear. A series of literature $[19,20]$ reported that OA was usually accompanied by an imbalance of intra-articular microenvironment, and synovial tissue and synoviocytes were reported to be the main factor, which suggested that the synovial cell microenvironment may be one of important regulatory factors in the pathogenesis of OA, and is expected to become a new target for the prevention and treatment of OA. However, the signaling pathway involved in the pathogenesis of the microenvironment of OA synoviocytes has not been reported. Synoviocytes are organizational structures that are important in maintaining the normal functions of joints and primarily consist of fibroblast-like synoviocytes and macrophagelike synoviocytes. Among those, fibroblast-like synoviocytes are not only the major component, but also the main functional cells of synovial tissue. In early OA, synovial shows hyperplasia and fibrosis, and secret inflammatory mediators, degradation enzymes and other factors to promote the degradation of cartilage cells, resulting in cell dysfunction of joint synovial, which is an important factor in the pathogenesis of OA, involving in the development of the whole pathological process [21, 22]. Thus, fibroblast-like synoviocytes are an important in vitro model for investigating the pathogenesis and drug treatment effects of OA. Therefore, in this research, we isolated and cultured fibroblast-like synoviocytes from shamoperated and OA rat in vitro, and detected VIP expression after VIP plasmid transfected into OA synoviocytes. The results showed the VIP expression in OA-synoviocytes reached its maximum levels at 7 th day, then declined over the next several days. This finding also provided an evidence of the administration frequency of in vivo study. Meanwhile, Brdu assay showed VIP treatment inhibited the proliferation of synoviocytes. Additionally, compared with sham synoviocytes, the protein expressions of Collagen II and OPG were significantly downregulated, and that of TNF- $\alpha$, IL-2, MMP- 13 and ADAMTS- 5 were obviously upregulated in OA synoviocytes treated with control plasmid. In contrast, after OA synoviocytes were treated with VIP plasmid, the protein expressions of these biomarkers were markedly restored. The result of the in vitro experiment was consistent with that of the in vivo experiment. The in vivo experiment demonstrated that the VIP plasmid could improve the pathological state and inhibit in flammatory cytokines, and the in vitro experiment showed that VIP plasmid could protect the synoviocytes, because after VIP plasmid treatment, the expressions of inflammatory cytokines and metalloproteinases in OA synoviocytes suppressed, while the expression of protective biomarkers of synoviocytes enhanced instead. In summary, VIP has the rapeutic effect on OA to some extent.

It was reported that the NF- $\mathrm{KB}$ signaling is a classic pathway involved in inflammatory response [23]. Therefore, further study was conducted to investigate whether OA pathogenesis and the mechanism of VIP plasmid related to NF- $\mathrm{KB}$ signaling pathway. A previous study reported that inflammatory cytokines, matrix-degrading enzymes and other factors could activate NF- $\kappa B$ signaling pathway. Once the NF- $k B$ signaling pathway is activated, the expression of phosphorylated ІкB will be rapidly up-regulated in by upstream ІкB kinase and contribute to a large number of inflammatory cytokines and chemokines, such as the expression of IL-6, IL-8, adhesion molecules and matrix-degrading enzymes, resulting in regulate inflammation and cell growth state; while newly synthesized IкB could inhibit the activation of NF- $\mathrm{kB}$ conversely [24-26]. In this study, we found the protein expressions of $\mathrm{p}-\mathrm{p} 65$ and $\mathrm{p}-\mathrm{I}_{\kappa} \mathrm{B} \alpha$ in OA synoviocytes significantly up-regulated and down-regulated, respectively. But after treatment with VIP plasmid for $48 \mathrm{~h}$, compared with the OA synoviocytes which treated with $\mathrm{NC}$ plasmid, p-p65 expression decreased and p- IкB expression increased in OA + VIP group. Thus, this study demonstrated that when OA occurred, inflammatory cytokines and matrix-degrading enzymes were increased, which activated the NF- $\mathrm{KB}$ signaling pathway. Then, as the NF- $k B$ signaling pathway was activated, the secretion of the inflammatory cytokines and matrix-degrading enzymes would be promoted, and the protective biomarkers of synoviocytes would decrease. However, the 
phenomenon of OA could be reversed by treatment with VIP plasmid.

In conclusion, all evidences above showed the VIP recombinant plasmid could inhibit the proliferation of synoviocytes, improve the pathological symptoms of OA disease and produce a therapeutic effect on OA via NF- $\mathrm{KB}$ signaling pathway. This study enriched the understanding of the pathogenesis of $\mathrm{OA}$, and provided a theoretical basis for the use of VIP plasmid on OA.

\section{Conclusion}

VIP recombinant plasmid can alleviate osteoarthritis effectively via inhibiting NF- $\mathrm{BB}$ signaling pathway.

\section{Acknowledgements}

All authors sincerely acknowledge the support given by the First Affiliated Hospital of Jinan University and Guangdong Pharmaceutical University, and thank the funding support.

\section{Funding}

This work was support by a grant from the Natural Science Foundation of Guangdong Province (NO. 2014A030313357).

\section{Availability of data and materials}

No applicable.

\section{Author's contributions}

$\mathrm{YL}$ and $\mathrm{HL}$ conceived the experiments; $\mathrm{YL}, \mathrm{SC}$ and $\mathrm{HL}$ designed the experiments; YL, SC, YY, CL, GZ and ZJ performed the experiments; YL, GZ and ZJ analyzed the data; $Y L$ and $H L$ prepared the manuscript. All authors read and approved the final manuscript.

\section{Ethics approval}

Animal experiments were performed in accordance with the Republic of China animal protection law (Chapter III: Scientific Application of Animals) and approved by the Animal Care and Use Committee of Guangdong Pharmaceutical University.

\section{Consent for publication}

Not applicable.

\section{Competing interests}

The authors declare that they have no competing interests.

\section{Publisher's Note}

Springer Nature remains neutral with regard to jurisdictional claims in published maps and institutional affiliations.

\section{Author details}

'Department of Orthopedics, The First Affiliated Hospital of Jinan University, Guangzhou 510630, China. ${ }^{2}$ Department of gynaecology and obstetrics, The First Affiliated Hospital of Jinan University, Guangzhou 510630, China.

\section{Received: 16 August 2017 Accepted: 15 January 2018}

Published online: 14 March 2018

\section{References}

1. Buckwalter JA, Mankin HJ, Grodzinsky AJ. Articular cartilage and osteoarthritis. Instr Course Lect. 2005:54:465-80.

2. Hsu DZ, Chu PY, Jou IM. Daily sesame oil supplement attenuates joint pain by inhibiting muscular oxidative stress in osteoarthritis rat model. J Nutr Biochem. 2016:29:36-40

3. Abramson SB, Attur M. Developments in the scientific understanding of osteoarthritis. Arthritis Res Ther. 2009:11(3):227.

4. Blanco FJ. Osteoarthritis: something is moving. Reumatol Clin. 2014;10(1):4-5.

5. Sacitharan PK, Vincent TL. Cellular ageing mechanisms in osteoarthritis. Mamm Genome. 2016;27(7-8):421-9.
6. Williams RO. Therapeutic effect of vasoactive intestinal peptide in collageninduced arthritis. Arthritis Rheum. 2002:46(1):271-3.

7. Juarranz Y, Abad C, Martinez C, Arranz A, Gutierrez-Canas I, Rosignoli F, Gomariz RP, Leceta J. Protective Effect of vasoactive intestinal peptide on bone destruction in the collagen-induced arthritis model of rheumatoid arthritis. Arthritis Res. Ther. 2005;7(5):R1034-45.

8. Jiang W, Gao SG, Chen XG, Xu XC, Xu M, Luo W, Tu M, Zhang FJ, Zeng C, Lei GH. Expression of synovial fluid and articular cartilage VIP in human osteoarthritic knee: a new indicator of disease severity? Clin Biochem. 2012;45(18):1607-12.

9. Keino H, Kezuka T, Takeuchi M, Yamakawa N, Hattori T, Usui M. Prevention of experimental autoimmune uveoretinitis by vasoactive intestinal peptide. Arch Ophthalmol. 2004;122(8):1179-84.

10. Zhang SZ, Shen JG, Liao ZX, Pan JP. construction of recombinant plasmid containing mouse vasoactive intestinal peptide gene and its expression in COS-7 cells. J. Zhejiang Univ. 2005:34(2):148-51.

11. Liu X, Liu W, Yang L, Xia B, Li J, Zuo J, Li X. Increased connexin 43 expression improves the migratory and proliferative ability of $\mathrm{H} 9 \mathrm{c} 2$ cells by Wnt-3a overexpression. Acta Biochim Biophys Sin Shanghai. 2007;39(6):391-8.

12. Hayami T, Funaki H, Yaoeda K, Mitui K, Yamagiwa H, Tokunaga K, Hatano H, Kondo J, Hiraki Y, Yamamoto T, Duong LT, Endo N. Expression Of the cartilage derived anti-angiogenic factor chondromodulin-I decreases in the early stage of experimental osteoarthritis. J Rheumatol. 2003:30(10):2207-17.

13. Xie GP, Jiang N, Wang SN, Qi RZ, Wang L, Zhao PR, Liang L, Yu B. Eucommia Ulmoides Oliv. Bark aqueous extract inhibits osteoarthritis in a rat model of osteoarthritis. J Ethnopharmacol. 2015;162:148-54.

14. Pritzker KP, Gay S, Jimenez SA, Ostergaard K, Pelletier JP, Revell PA, Salter D, van den Berg WB. Osteoarthritis cartilage histopathology: grading and staging. Osteoarthr Cartil. 2006;14(1):13-29.

15. Juarranz MG, Santiago B, Torroba M, Gutierrez-Canas I, Palao G, Galindo M, Abad C, Martinez C, Leceta J, Pablos JL, Gomariz RP. Vasoactive intestinal peptide modulates proinflammatory mediator synthesis in osteoarthritic and rheumatoid synovial cells. Rheumatology (Oxford). 2004;43(4):416-22.

16. Gonzalez-Rey E, Fernandez-Martin A, Chorny A, Delgado M. Vasoactive intestinal peptide induces $C D 4+, C D 25+T$ regulatory cells with therapeutic effect in collagen-induced arthritis. Arthritis Rheum. 2006;54(3):864-76.

17. Assirelli E, Pulsatelli L, Dolzani P, Platano D, Olivotto E, Filardo G, Trisolino G, Facchini A, Borzi RM, Meliconi R. Human osteoarthritic cartilage shows reduced in vivo expression of $\mathrm{IL}-4$, a chondroprotective cytokine that differentially modulates IL-1 beta-stimulated production of chemokines and matrix-degrading enzymes in vitro. PLoS One. 2014;9(5):e96925.

18. Jiang W, Wang H, Li YS, Luo W. Role Of vasoactive intestinal peptide in osteoarthritis. J Biomed Sci. 2016;23(1):63.

19. Ayral X, Pickering EH, Woodworth TG, Mackillop N, Dougados M. Synovitis: a potential predictive factor of structural progression of medial tibiofemoral knee osteoarthritis - results of a 1 year longitudinal arthroscopic study in 422 patients. Osteoarthr Cartil. 2005:13(5):361-7.

20. Loeuille D, Chary-Valckenaere I, Champigneulle J, Rat AC, Toussaint F, Pinzano-Watrin A, Goebel JC, Mainard D, Blum A, Pourel J, Netter P, Gillet P. Macroscopic and microscopic features of synovial membrane inflammation in the osteoarthritic knee: correlating magnetic resonance imaging findings with disease severity. Arthritis Rheum. 2005;52(11):3492-501.

21. Steenvoorden MM, Bank RA, Ronday HK, toes RE, Huizinga TW, DeGroot J. Fibroblast-like synoviocyte-chondrocyte interaction in cartilage degradation. Clin Exp Rheumatol. 2007;25(2):239-45.

22. Nair A, Kanda V, Bush-Joseph C, Verma N, Chubinskaya S, Mikecz K, Glant TT, Malfait AM, Crow MK, Spear GT, Finnegan A, Scanzello CR. Synovial fluid from patients with early osteoarthritis modulates fibroblast-like synoviocyte responses to toll-like receptor 4 and toll-like receptor 2 ligands via soluble CD14. Arthritis Rheum. 2012;64(7):2268-77.

23. Zhao JJ, Guo YQ, Yang DP, Xue X, Liu Q, Zhu LP, Yin S, Zhao ZM. Chlojaponilactone B from Chloranthus japonicus: suppression of inflammatory responses via inhibition of the NF-kappaB signaling pathway. J Nat Prod. 2016;79(9):2257-63.

24. Bonizzi G, Karin M. The two NF-kappaB activation pathways and their role in innate and adaptive immunity. Trends Immunol. 2004;25(6):280-8.

25. Baldwin AS Jr. The NF-kappa B and I kappa B proteins: new discoveries and insights. Annu Rev Immunol. 1996;14:649-83.

26. Li Y, Ahmed F, Ali S, Philip PA, Kucuk O, Sarkar FH. Inactivation of nuclear factor kappaB by soy isoflavone genistein contributes to increased apoptosis induced by chemotherapeutic agents in human cancer cells. Cancer Res. 2005;65(15):6934-42. 